\title{
Research on the Dynamic Cost Management of the Construction Project and the Optimization of the Cost Control
}

\author{
Xiaoni Jia
}

Xi'an International University, Xi'an Shaanxi, 710077

Keywords: Cost Control; Dynamic Management; Project Cost; Construction

\begin{abstract}
Project cost means the total monetary expenses, which includes the monetary consumption on material resource, on human resource, and on financial resource, during the process of constructing a building from the beginning to the end. The management of the project cost and the cost optimization aim for making the total monetary consumption that is spent in the construction project could be utilized reasonably, so as to achieve the objective of saving money. To manage the construction project reasonable is the basic method that could promote the construction enterprise to control the cost, and it is the key factor for their cost control and cost optimization so that the enterprises could improve their competitive advantages. By analyzing the conceptions, the principle, and the implementation strategy of the dynamic cost management of the construction project, and the optimistic method of it, this thesis discusses the best strategy on project cost management and the cost control.

The development of the science and economy accelerates the urbanized construction of China, and it promotes the development of the construction enterprises in China, at the some time, the competition between the construction enterprises is becoming fiercer and fiercer. Therefore, construction enterprises should adopt useful methods for reducing the project cost, these methods could not only ensure the construction quality, but also save the cost of the enterprise, so that the enterprises could improve their efficiency of the capital utilization and the competitive powers. The Chinese construction enterprises have been strived for improving the project cost management abilities and the cost controlling abilities for a long time, it is the dynamic management of the project cost that is a kind of reflection on the enterprises' endeavors for reducing the cost. By the virtue of the dynamic management, the enterprise could manage every stage and segment of the construction project well, so that the pace of construction could be accord with the schedule, and the cost that is expensed on the construction and the total cost of the project could be controlled well.
\end{abstract}

\section{Analysis on conceptions of the project cost dynamic management and cost optimization control}

The cost management of the construction project includes a lot expenses such as the expense on construction, materials, purchasing and selling equipments, hiring equipments, and installing equipments, etc. there are a lot factors influence the managerial effect, the human factor is the most influencing factor. Dynamic management is an important managerial mean which comes from the long-term developmental experiences of the construction enterprises. According to the actual developmental situation of the construction industry, the construction enterprises could analyze the specific construction project comprehensively by the dynamic management method, and program 
more scientific and more reasonable managerial method for controlling the project cost, so as to control the cost on the premise of ensuring the construction quality and reducing the cost of the enterprise to the largest extent, and maximizing the benefits ${ }^{[1]}$. The dynamic management requires controlling the cost from all the segments of the construction project, considering the project overall, adopting the dynamic controlling method, supervising the every segments during the planning and construction process of the project, so as to control and optimize the cost and then increase the benefits of the enterprises.

\section{The principle that the dynamic cost management of construction project and the cost optimization and control}

The whole life circle of the construction project means the whole period from the completion of a building until it to be destructed; while the whole life circle management and control means the total expenses during the two stage----the construction stage and the using stage, i.e., the total expenses of the planning period, the construction period, the using period, and the destructive period $^{[2]}$. There are various kinds of factors that influence the cost of the construction project in different stage, and the cost is uncertain. So, to manage and control the whole life circle of the construction project could minimize the project cost and improve the management on the investment decision-making and on the design of the construction scheme.

The present construction project cost management mainly according to the budget that is from the construction drawings and the settlement when the construction is finished; although this method is relative effective, but it still has some defectives. So, to limit the project cost to a small and reasonable extent, the construction enterprises could not only reduce the unreasonable investment, but also reasonably allocate the funds to every segment of the project, and then the enterprises could make a reasonable investment decision of the permanent assets. It is the whole process management and control that could achieve this kind of effect, it could control every segment of the project from the beginning until the completion well, so to speak, and it should be adopted in the whole project period ${ }^{[3]}$. At present, there are many methods have been adopted to the whole process control such as analysis, compare, examination, supervision, etc; by these methods, the enterprises could constantly find the problems during the construction process timely, and then to solve the problems, so as to control the construction project well.

The cost management of the construction project not only focuses on a single segment of the project, but also is a kind of overall management which involves a lot of cost factors such as time, quality, and environment, and so on. To consider the projects with all these factors are very crucial. For reducing the project cost, if the construction enterprises only adopt the quantitative management, so the quality of the project, the time limit of the project, and the safety of the project would not be secured effectively. At the some time, these factors often influence the others. For example, shortening the construction period, the quality of the project will decline, and if the construction period is extended, the cost of the project will be increased. Therefore, the enterprises should supervise the project quality strictly and pay more attention to the environmental safety, so as to reduce the cost of the project and actualize the goal of the dynamic cost management of the construction project and the cost optimization control. The construction enterprises should know very well about the factors that influence the cost of the project, analyze the factors and forecast the factors, and coordinate the relationship between these factors, so as to actualize the best managerial and controlling results.

To complete a construction project is a special but simplex activity, and it expense a lot of funds; the overall management and control is a very important way to control the cost of the project. 
A construction project often takes a long time so that the prices of the materials are fluctuant, so the enterprises should analyze the factors that influence the actual cost deviate from the budget, and adopt the effective countermeasures to manage the factors, so that the dynamic cost management of the construction project could be carried out well and the cost could be controlled well.

\section{The countermeasures of the dynamic cost management of construction project and the cost optimization control.}

The preparation phase mainly includes the constructive decision-making, the planning of the constructive draft, the bidding and tendering. The result of the bidding and tendering is the important phase that influences the cost of the construction project. The essential parts of the bidding and tendering are the planning of the project, the way of construction, the construction materials, and the construction equipments. In the phase, the enterprise should choose the best project planning and the best arrangement and method for the construction, choose the materials that are higher quality but reasonable price, and the proper construction equipments. At the some time, the bidding and tendering must be open and justice, the base number of a tender must be reasonable; it is necessary to overall consider the tenders' qualification level, credit standing, resource capabilities, and their service abilities. The employee of the project should choose the tenders with good abilities above, this could not only reduce the cost of the project, but also decline the risks from the very beginning of the project, so as to optimize and control the cost of the construction project ${ }^{[4]}$.

It is the construction phase that the employee of the construction invests a lot of resources to the project, so it is the important phase of the dynamic cost management and the optimization control of the cost. In this phase, the enterprises should follow all the rules in the contract, and coordinate the relationships of all the participators, and design a series of effective planning that could control the cost of the project, so that all the participators could gain the highest benefits. We take the dynamic cost management of a construction project for example as below, to summarize the managerial and controlling strategies during the construction phase.

First, the engineer department of this instance may modify the construction planning, even may modify it several times, after the modification, the department reports the modified planning to the employee of the construction for approval, and then the constructors construct the project following the best construction planning, so as to reduce the cost and ensure the quality and the schedule of the project and achieve the economic result that investing least, but gaining most. For the temporary constructions, the employer of the construction project could use the detachable house; the employer of the construction project had better using the construction mechanical equipments that are their own, if they don't have the equipments, they also could hire them.

Second, the equipment expense, material expense and the labor expense are three important expenses, it is very important to manage and control these expenses. For controlling the expense on the equipments, the enterprise should choose the creditworthy partners that have a lot of high-quality equipments, so as to ensure the safety and control the cost. For the material expense, the enterprise should compare the quality and the price of the materials with the different providers, and choose material that is with high quality and reasonable price, at the some time, sign the contract with the providers according to the construction contract, so that the contract with the provider could restrict the providers so that the provider must provide the good materials or the provider should be punished by monetary mean. For controlling the labor expense, the enterprise should cooperate with the effective labor service company so as to ensure the investment on labor is effective and keep a reasonable level ${ }^{[5]}$. 
At last, planning the schedule of construction scientifically, controlling the construction quality strictly. In general, the time limit of a construction project is confirmed at the phase of bidding and tendering, while during the actual construction phase, the enterprise should adjust the time limit and the construction schedule reasonably. The enterprise should coordinate the relationship between the quality and the cost, to reduce the cost under the premise that ensuring the quality of the project.

Because the construction project is influence by many uncertain factors, so the construction planning may be changed during the actual construction process. The changes may influence the cost of the project. Therefore, when the planning of the project will be changed, the changes should be legal and in accord with the procedure, and the leading official must approve the alteration before it be carried out. Especially, if the time limit of the project will be prolonged, the relevant expenses would be increased, so it is necessary to collect the information overall. In general, the construction project should be constructed according to the original planning, if it must be altered, it also should be altered according to the contact. The alteration of the planning requires the cooperation of the supervision department, planning department, the employer of the construction, and the employee of the construction, only when these relevant departments agree with the alteration could the planning department alter the planning draft and write the reminder for the others; then, the supervision departments approve it and put it into force; after the approval, the others take charge of carrying out the alteration ${ }^{[6]}$.

After the construction and the acceptance check of the project, the employer of the construction should settle accounts of the cost of the project; this is the last phase of the project cost control. The employer of the construction should collect, sort out, analyze, and integrate the relevant settlement documents, so as to ensure a right and integrity settlement account. In general, the last cost consist of the planning cost, the cost of alteration, and the expense on certification, etc, so the employer should audit all kind of expense carefully; the staff of the project department should analyze the cost, and analyze the relationship between the settlement and the cost, the purchased quantity and the used quantity; if there are serious problem, it is necessary to find out the reason as soon as possible, and then, to solve it. The enterprises also should summarize the economic techniques and experiences during the project so as to guide the following projects on saving the costs of the projects.

\section{References:}

[1]Zhang Wenjie. Research on Dynamic Management of the Construction Project Cost and the Cost optimization Control[J]. Low Carbon World, 2017,(25):251-252.

[2]Chen Xiaoli. Research on Dynamic Management of the Construction Project Cost and the Cost optimization Control[J]. Jiang Xi Jian Cai, 2017,(12):220.

[3]Zhang Xianlan. Deliberation on the Dynamic Management of the Construction Project Cost and the Cost Optimization Control[J]. Doors and Windows, 2017,(06):177.

[4]Luo Xueqiong. Dynamic Management of Construction Project Cost and Cost Optimization Control[J]. Construction Materials \& Decoration, 2017,(07):163-164.

[5]Yang Shengshan. Research on Dynamic Management of the Construction Project Cost and the Cost optimization Control[J]. Architectural Knowledge, 2016,(09):171+176.

[6]MiaoLiqin. Analysis on Dynamic Management of the Construction Project Cost and the Cost optimization Control[J]. Jiang Xi Jian Cai, 2015,(16):267-268. 